www.periodicos.unimontes.br/index.php/caminhosdahistoria

\title{
SABERES POPULARES, POLÍTICAS CULTURAIS E PARTICIPAÇÃO SOCIAL: DUAS EXPERIÊNCIAS BRASILEIRAS
}

\author{
Daniel Roberto dos Reis Silva ${ }^{1}$ \\ Edilberto José de Macedo Fonseca ${ }^{2}$ \\ Laíze Soares Guazina ${ }^{3}$
}

Resumo: Nos últimos anos é notório o crescente número de projetos e iniciativas norteados por metodologias participativas e/ou colaborativas no Brasil, ligados a diferentes instituições, como universidades, museus, centros de pesquisa e de fomento às políticas públicas e recorrentemente voltados para comunidades periféricas e/ou tradicionais, pautados por discursos afirmativos, democratização de saberes e reconhecimento da diversidade cultural. No intuito de balizar o debate e expor alguns argumentos sobre este campo, propomos refletir de modo mais detalhado sobre algumas iniciativas desenvolvidas a partir dos anos 1980 na cidade de Januária (MG), voltadas ao campo do artesanal e paisagem sonora ditos tradicionais. Num momento em que se identifica um constante assédio em torno dos ditos "saberes populares", parece-nos oportuno propor uma reflexão sobre os possíveis alcances destas práticas e os justos sentidos de protagonismo que de fato almejam.

Palavras-chave: Políticas Culturais; Metodologias Participativas; Sala do Artista Popular; Ponto de Cultura; Januária.

Abstract: In recent years, the growing number of projects and initiatives guided by participatory and / or collaborative methodologies in Brazil, linked to different institutions, such as universities, museums, research centers and public policy development centers. Recurrently aimed to peripheral and/or traditional communities, these projects and initiatives are guided by affirmative speeches, democratization of knowledge and recognition of cultural diversity. In order to guide the debate and expose some arguments about this field, we propose to reflect in more detail on some initiatives of traditional crafts and soundscape developed since the 1980s in the city of Januária (Brazil). At a time when a constant attention around the so-called "popular knowledge" is identified, it seems appropriate to propose a reflection on the possible scope of these practices and the just meanings of protagonism that they really aim for.

Keywords: cultural policies; participatory methodologies; Popular Artist Room; Culture Point; Januária.

\footnotetext{
${ }^{1}$ Doutor em Antropologia pela UFRJ. Pesquisador do Centro Nacional de Folclore e Cultura Popular (IPHANDF). Professor do Mestrado Profissional em Preservação do Patrimônio Cultural-IPHAN. E-mail: drreis55@yahoo.com.br. ORCID: https://orcid.org/0000-0002-2366-0285

${ }^{2}$ Doutor em Música pela UNIRIO. Professor adjunto no curso de Produção Cultural da Universidade Federal Fluminense (UFF). E-mail: dil.fonseca@ gmail.com. ORCID: https://orcid.org/0000-0003-0947-4440.

3 Doutora em Música pela UNIRIO. Professora na UNESPAR. E-mail: laizeg@ig.com.br. ORCID: https://orcid.org/0000-0001-7203-3387
} 


\section{Introdução}

Política cultural se tornou, nas últimas décadas, um termo cada vez mais complexo e de precária definição, assim como seus processos de institucionalização e gestão. Outrora visto como um conjunto de ações do Estado por meio de normas jurídicas ou intervenções diretas (COELHO, 1997), posteriormente, Nestor Garcia Canclini (2001) sugeriu a necessidade de repensá-lo considerando a complexificação das redes de interações culturais, o caráter transnacional de processos simbólicos e materiais, bem como seus fluxos comunicacionais e migratórios. Antônio Rubim (2011) acrescentou ainda, que há um emaranhado conjunto de atores estatais e não estatais atuando neste campo. Assim, por um lado, o Estado deve ser pensado em suas diferentes escalas (do municipal ao internacional) e formas de ação (interministeriais ou de diferentes órgãos de um mesmo ministério). Por outro, deve-se atentar para a complexidade de atores da sociedade civil indicando, para além do mercado, a presença cada vez intensa de associações, ONGs, movimentos sociais organizados. Contudo, o autor afirma:

Somente políticas submetidas ao debate e crivo públicos podem ser consideradas substantivamente políticas de cultura. Sempre é bom lembrar que tal negociação acontece entre atores que detêm poderes desiguais e encontram-se instalados de modo diferenciado no campo de forças que é a sociedade capitalista contemporânea. Assim, políticas públicas de cultura podem ser desenvolvidas por uma pluralidade de atores político-sociais, não somente o Estado, desde que tais políticas sejam submetidas obrigatoriamente a algum controle da sociedade, por meio de crivos públicos, que envolvem sempre a participação nos processos de debates e deliberativos. (RUBIM, 2011, p. 70) ${ }^{4}$

Antônio Rubim nos lembra que toda política cultural traz embutida uma dada concepção de cultura. Assim, a amplitude do conceito de cultura utilizado define os recortes e seleções sobre que grupos poderão estar inclusos, quais serão excluídos e quais questões serão enfrentadas. De tal forma, observar os objetivos e as metas das políticas culturais permitem observar "quais as interações pretendidas entre as intervenções político-culturais e as transformações buscadas na sociedade" (RUBIM, 2011, p. 68).

Em relação ao Brasil, em específico, Lia Calabre (2019) chama ainda a atenção ao fato de que, se o direito à cultura foi posto pela constituição de 1988 e legislações estaduais e municipais, o desafio é tornar isso de fato, realidade. A visão muitas vezes limitada ao caráter episódico e de evento, a escassez de recursos, as descontinuidades entre gestões, a necessidade de formação ampla e multidisciplinar do quadro de gestores, bem como a maior

4 Todas as citações desse artigo preservam a escrita originalmente encontrada nas edições transcritas. 
participação das comunidades envolvidas para elaboração das políticas de cultura são desafios indicados pela autora a serem superados em direção de uma política cultural que alcance direitos de cidadania e democratização cultural de modo amplos.

Considerando esse arcabouço, buscamos abordar aqui as políticas de cultura voltadas para os saberes populares no Brasil, tendo como recorte temporal as décadas de 1980-2000, período que corresponde ao processo de redemocratização do país, edição da Constituinte de 1988 e seus pressupostos sobre o direito e acesso à cultura, com a criação de alguns programas embrionários até o desenvolvimento de uma série de iniciativas nos anos 2000, para além de um conjunto de transformações teórico e metodológicas nas ciências humanas como a pauta decolonial, crises de modelos representacionais e de escrita, além do impacto de movimentos minoritários sobre as formas de se pensar e produzir conhecimento.

De forma estratégica optamos por nos debruçar sobre um território específico, a cidade de Januária (MG), para observar como, eventualmente, distintos programas são elaborados, executados e dialogam ou não entre si e com a população local. Dadas as limitações do espaço de um artigo, recortamos duas ações lá implementados, o Programa Sala do Artista Popular (SAP), criada em 1983, realizado pelo Centro Nacional de Folclore e Cultura Popular, e o Programa Ponto de Cultura, criado em 2004, no âmbito do Ministério da cultura.

Este recorte nos oferece uma rica amostragem de análise considerando fatores como: a) serem políticas institucionais voltadas para os saberes populares visando sua promoção de modo dialógico; b) são operacionalizadas por meio de seleção feita por especialistas e editais, em que o estado busca captar ações de cultura já existentes; c) buscam incorporar os saberes populares para que sejam seus representantes os próprios autores das ações que serão desenvolvidas; d) podem ser observadas na perspectiva de circuito.

A noção de circuito permite a compreensão das culturas populares a partir da circulação de seus atores em diversas esferas culturais, no caráter multi-situado destas pessoas, para além de uma visão que congela determinado personagem a uma dada manifestação (FONSECA, 2009; REIS, 2013; OSÓRIO, 2012). Essa perspectiva, considerada nas dimensões diacrônica e sincrônica, evidencia que diversas ações de política cultural incidem sobre determinados grupos e territórios propondo diferentes olhares. Identifica-se assim: 1) que uma mesma instituição pode lançar diferentes olhares sobre um determinado bem cultural ao longo do tempo; 2) que diferentes órgãos atuam com diferentes ações sobre um mesmo bem cultural; 3 ) ou ainda como diferentes órgãos propõe ações ao longo do tempo; 4) distintas formas de diálogo e participação dos grupos como agentes ativos no processo de elaboração e execução. 
Para construção de nosso argumento recorremos a diferentes fontes. Para além da literatura sobre o assunto abordado, os arquivos do Centro Nacional de Folclore e Cultura Popular, os catálogos produzidos pelo Programa SAP, os dados de nossas pesquisas de campo realizadas em diferentes momentos, bem como relatórios sobre a Plano Nacional de Cultura 5 .

Do ponto de vista teórico, para além da literatura sobre as políticas de cultura, nos ancoramos no aporte da antropologia e etnomusicologia, visto que abordamos saberes sobre objetos e paisagens sonoras em um dado local e grupo de pessoas. Essa perspectiva se justifica sobretudo no que tange às possibilidades que oferece para dialogar com as políticas culturais e, em especial, com um conjunto de questões que tem nos mobilizado enquanto pesquisadores e estão o cerne da proposta deste artigo: De que maneiras a multiplicação de atores sociais atuando na construção de políticas culturais vem impactando as políticas de cultura voltadas para os saberes populares? Qual a relevância de ações participativas na potencialização das mesmas? Qual o papel dos gestores neste cenário? Há experiências na história recente do Brasil apontando para este caminho? Em que medida?

Começamos assim, comentando sobre os diálogos entre antropologia e etnomusicologia sobre tais questões, para, em seguida, nos debruçarmos sobre os estudos de caso indicados a fim de avaliar de que forma estas ideias se aplicam ou não à realidade nacional e aos casos abordados.

\section{Saberes populares, participação e colaboração na produção do conhecimento}

É notório observar que há, recentemente, um vertiginoso interesse por metodologias de pesquisa pautadas em noções participativas. Oriundo de diferentes instituições, como universidades, museus, centros de pesquisa e de fomento às políticas públicas, esse ímpeto é recorrentemente voltado para comunidades periféricas e/ou tradicionais, assentado em discursos afirmativos, democratização de saberes e reconhecimento da diversidade cultural.

No campo antropológico, as crises quanto a autoridade etnográfica e formas de representação do outro na disciplina, que vem ocorrendo desde as décadas de 1970-80, apontaram para necessidade de se repensar modelos de se fazer etnografia (CLIFFORD \& MARCUS, 1986; CLIFFORD, 2002; IMPEY, 2002; SHELEMAY, 1997). Antropologia

5 Segundo definição oficial: "O Plano Nacional de Cultura (PNC) é um conjunto de princípios, objetivos, diretrizes, estratégias, ações e metas que orientam o poder público na formulação de políticas culturais. Previsto no artigo 215 da Constituição Federal, o Plano foi criado pela Lei ${ }^{\circ} 12.343$, de 2 de dezembro de 2010. Seu objetivo é orientar o desenvolvimento de programas, projetos e ações culturais que garantam a valorização, o reconhecimento, a promoção e a preservação da diversidade cultural existente no Brasil." Disponível em: http://pnc.cultura.gov.br/entenda-o-plano/ Acesso em: 03/02/2019. 
dialógica, partilhada, polifônica, foram algumas das alternativas que ganharam força neste momento e cujo cerne comum é a horizontalização das formas de produzir conhecimento, ou da partilha das vozes que emanam do saber produzido.

Essa crise de representação e formas de escrita de si e do outro, embora tenha afetado a antropologia e a etnomusicologia no cerne de seus princípios epistemológicos, parece ter seus efeitos nas ciências humanas de modo geral, dialogando entre outras questões, com as demandas pós-coloniais, com as várias vozes que emergem reivindicando seu lugar na escrita de seu passado, seu presente e suas culturas, bem como o olhar crítico sobre a produção até então elaborada sobre tais grupos.

No meio etnomusicológico, esse crescimento pode ser percebido pela ampliação de trabalhos publicados que expressam algum tipo de vinculação teórico-metodológica às propostas envolvendo a pesquisa ação participativa. Conforme Guazina (2015), a partir da análise dos textos presentes nos Anais dos Encontros Nacionais da Associação Brasileira de Etnomusicologia, de 2002 a 2013, tais textos descrevem, em maior ou menor proporção, o desenvolvimento de estratégias de trabalho com forte acento social que envolvem, em alguma medida, ações educativas para o grupo de trabalho ou as comunidades em que as pesquisas são desenvolvidas. Os grupos de trabalho, habitualmente compostos por pesquisadores/as acadêmicos e participantes reconhecidos/as como pesquisadores/as "não acadêmicos", costumam desenvolver suas pesquisas com embasamento significativamente amparado nas contribuições de Paulo Freire, indicando suas relações com as perspectivas emancipatórias da educação popular (GUAZINA, 2018).

Conforme analisado por Cambria, Fonseca e Guazina (2016), no caso do Brasil, é praticamente impossível abordar de modo resumido o que tem levado a etnomusicologia brasileira a engajar-se em propostas participativas e colaborativas. Os/a autores/a analisam que uma relação de colaboração pode significar coisas diferentes e podem acabar por estabelecer laços estreitos que geram diferentes modos de ação, podendo perdurar por longos períodos. Essas são características também presentes na Antropologia.

Cambria, Fonseca e Guazina (2016) analisam algumas diferenças, conexões e fronteiras ao questionarem as relações estabelecidas entre etnomusicólogos/as, pessoas participantes das pesquisas e o conhecimento produzido por elas nas pesquisas. Para os/a autores/a, essas relações podem ser organizadas em três tendências principais. A primeira tendência se concentraria no desenvolvimento de estudos "sobre" as pessoas (trabalhos com perfil acadêmico/teórico) e a música que elas fazem; a segunda, se caracterizaria pelo uso do conhecimento acumulado "para" elas (trabalhos "aplicados" ou "práticos"). Uma terceira 
tendência seria desenvolvida como alternativa às outras duas e se caracterizaria pela proposta de produzir o conhecimento "com" as pessoas das comunidades estudadas. Tal perspectiva ampara-se nas formulações de Paulo Freire e, de modo mais geral, na pesquisa-ação participativa. Nesta tendência, o diálogo e a colaboração tornam-se bases para a formulação de um conhecimento engajado social e politicamente, que tem a mudança social como objetivo último e que busca estabelecer as relações entre pesquisadores/as acadêmicos/as e participantes a partir da concepção sujeito/sujeito (e não mais sujeito/objeto).

Existe uma clara conexão entre as propostas participativas e colaborativas desenvolvidas atualmente na etnomusicologia brasileira e as contribuições de autores envolvidos com a pesquisa-ação participativa latino-americana, a partir da década de 60 e 70 . Os dois principais autores que embasam tais propostas são Paulo Freire e Orlando Fals Borda, ao desenvolverem a pesquisa-ação (investigación-acción) a partir de duas vertentes: a educacional, de Freire, e a sociológica, de Fals Borda (GAJARDO, 1999).

Apesar da diversidade de abordagens, algumas características comuns podem ser apontadas, como

1) "explicitação de uma intencionalidade política e uma opção de trabalho junto aos grupos mais relegados da sociedade; 2) integração de investigação, educação e participação social como momentos de um processo centrado na análise daquelas contradições estruturais que mostram com maior clareza os determinantes estruturais da realidade vivida endentada como objeto de estudo"; 3) "incorporação de setores populares como atores de um processo de conhecimento, onde os problemas se definem em função de uma realidade concreta e compartilhada, cabendo aos grupos decidir a programação de estudo e as formas de encará-la" (GAJARDO, 1999, p. 1617).

Para Gajardo, embora se reivindique a Paulo Freire a introdução do enfoque sóciopolítico na educação e da pesquisa educativa no contexto latino-americano, são os trabalhos do sociólogo Fals Borda que darão maior densidade ao debate a partir das propostas da pesquisa-ação (investigación-acción) e que caracterizarão os chamados "estilos participacionistas de pesquisa”. Tal como abordado por Gajardo (1999), os trabalhos de Fals Borda incluem a indicação de princípios metodológicos que compreendem um compromisso com os movimentos populares pautado por autenticidade, antidogmatismo, devolução sistemática, retroalimentação de intelectuais orgânicos, ritmo e equilíbrio entre ação e reflexão e o desenvolvimento de uma ciência baseada em técnicas dialógicas.

Se nas décadas 60 e, especialmente, 70 vemos surgirem as abordagens de Freire e Orlando Fals Borda tal como descrito acima, é no início da década de 80, caracterizada pela presença de regimes autoritários e modelos econômicos excedentes na América Latina, que 
veremos o surgimento da pesquisa participante. Conforme Gajardo, a pesquisa participante sintetizará as várias características das propostas das duas décadas anteriores, em diálogo com os acontecimentos daquele momento. É dessa maneira que, com ênfase na produção e comunicação de conhecimentos, que a pesquisa participante passa a agregar novos objetivos (GAJARDO, 1999, p. 40):

\begin{abstract}
1) promover a produção coletiva de conhecimentos, rompendo com o monopólio do saber e da informação e permitindo que ambos se transformem em patrimônio [sic] dos grupos subalternos; 2) promover a análise coletiva do ordenamento da informação e da utilização que dela se pode fazer; 3) promover a análise crítica, utilizando a informação ordenada e classificada a fim de determinar as raízes e as causas dos problemas e as possibilidades de solução; 4) estabelecer relações entre os problemas individuais e coletivos, funcionais e estruturais, como parte da busca por soluções coletivas aos problemas enfrentados.
\end{abstract}

Convém considerar que existem diferentes nomenclaturas para denominar esses modos de fazer pesquisa. Tanto um mesmo termo pode ser utilizado por diferentes perspectivas quanto diferentes termos, normalmente próximos, podem se referir a perspectivas similares ou diferentes, em maior ou menor grau. A pluralidade de termos dá visibilidade à existência de perspectivas teórico-metodológicas que têm similaridades, porosidades, mas também diferenças, tendo em vista os diferentes contextos históricotemporais em que surgem e as diversas características que possuem.

Thiollent e Oliveira (2016, p.357-358) consideram essa pluralidade como um "leque de possibilidades", mesmo que esses termos tenham significados diferentes e representem, na prática, diferenças na organização do projeto de pesquisa, e na situação e comunicação entre pesquisadores e atores envolvidos. Contudo, os autores se referem a um exemplo importante da implicação de tais proximidades de termos, a saber, a confusão por vezes existente entre a observação participante, realizada na etnografia e na antropologia, e a pesquisa participante, como concebida e praticada na educação e em outras áreas, especialmente na América Latina. A pesquisa participante deu origem à pesquisa-ação participante proposta por Fals Borda e que se expande para as Américas do Norte e Sul.

Nesse cruzamento entre produção de conhecimento, participação e saberes populares, não podemos deixar de mencionar também os estudos de folclore, vertente que manteve forte diálogo com antropologia, sociologia, etnomusicologia e educação. Se em boa parte do meio acadêmico brasileiro a produção do chamado Movimento Folclórico (VILHENA, 1997) ficou estigmatizada como uma produção diletante e romântica é inquestionável a contribuição deixada por estes pesquisadores. Estudos, acervos documentais, sonoros, museológicos, 
instituições culturais foram sistematicamente produzidos e servem hoje de base para muitos estudos de uma antropologia e/ou etnomusicologia das culturas populares.

No âmbito da etnomusicologia, os estudos do folclore são comumente posicionados como parte do processo de construção da área no Brasil, e os/as folcloristas como alguns/as dos/as "precursoras/es" (LÜHNING et al, 2017). Conforme os mesmos autores (2017, p. 59), "folclore" foi um termo introduzido (...) e utilizado para denominar "as tradições musicais de transmissão oral, presentes em todas as regiões do país". Naquele momento e até as últimas décadas do século XX, muitas das influências dos folcloristas podiam ser percebidas. Seus trabalhos, entre o fim do século XIX e início do século XX, concebiam que tais tradições musicais conteriam traços essenciais das culturas em que teriam sido formadas.

Muitas das concepções e práticas do movimento folclorista não são partilhadas pela etnomusicologia e pela antropologia da atualidade e, de fato, desde longa data. Contudo, é necessário considerar que a perspectiva horizontalizada de estudo das culturas populares não é produto contemporâneo e que, no âmbito do folclore, remonta a própria construção deste campo de saber no Brasil.

No $1^{\circ}$ Congresso Brasileiro de Folclore realizado em 1951 no Rio de Janeiro, momento de busca por institucionalização deste campo no meio acadêmico e das instituições culturais, foi redigida a Carta do Folclore Brasileiro. O documento pretendia fornecer as diretrizes para os estudos de folclore no Brasil bem como as políticas públicas que pudessem vir a se desenvolver a partir de então. Um capítulo dedicado à pesquisa apresenta o tópico: "Recomenda-se, como metodologia de pesquisa, atuação participativa, integrando pesquisador e pesquisado em todas as etapas de apreensão, compreensão e evolução dos resultados da pesquisa à comunidade.” (IBECC, 1951). Embora preconize a intenção de estudos participativos, uma análise minuciosa sobre o quanto e em que contextos este princípio foi de fato levado a cabo pelos folcloristas é um estudo ainda a ser feito.

É importante sublinhar, no entanto, que a partir dos anos 70 os saberes populares passam a despertar cada vez mais a atenção de disciplinas como antropologia, etnomusicologia, história, entre outras. A própria geração de pesquisadores de cultura popular que sucede aquela que institucionaliza os estudos de folclore no país já é majoritariamente formada nos departamentos universitários e teoricamente orientada por tais disciplinas.

As perspectivas participacionistas de pesquisa contribuem com uma mudança de olhar para as culturas populares, trazendo algumas renovações sobre formas de produzir conhecimento neste campo e seus métodos. É um período que coincide justamente com as crises epistemológicas e reformulações conceituais das disciplinas das ciências humanas 
como indicado acima. É, também, quando começa a convergir diferentes olhares disciplinares organizados e propostas dialógicas e polifônicas de produzir conhecimentos voltados para as culturas populares. As experiências que comentaremos em seguida, refletem esse contexto.

\section{Januária (MG)}

O município de Januária está situado no noroeste do Estado de Minas Gerais, na região do médio São Francisco, à margem esquerda do rio homônimo. Foi elevado à condição de cidade no ano de 1860, ainda com denominação de Porto do Salgado, passando à alcunha atual vinte e quatro anos depois. ${ }^{6}$ A navegação pelo Rio São Francisco foi, desde os tempos coloniais, porta de entrada da interiorização no Brasil fazendo com que a região se tornasse um vetor de convergência e interação entre grupos sociais, indivíduos, bens e serviços. Com uma população atual de cerca de 68 mil habitantes distribuídas em seus oito distritos ${ }^{7}$, constitui-se num polo que, juntamente com as cidades vizinhas, abriga uma enorme e importante riqueza cultural e histórica.

Particularmente em relação às manifestações culturais, a região é um tradicional celeiro tanto de uma singular, variada e tradicional produção artesanal em barro, bambu, madeira e tecido quanto de grupos performativos ligados ao chamado catolicismo popular, como as Folias de Reis, as danças de São Gonçalo e a Cavalhada. Essa diversidade e riqueza cultural da região atraíram diversos pesquisadores e, já na década de 1960 o pesquisador Joaquim Ribeiro realizou uma significativa documentação na região a pedido da Campanha de Defesa do Folclore Brasileiro e que resultou na obra $O$ Folclore de Januária, publicado em 1970 (FONSECA, 2009).

\section{Programa Sala do Artista Popular}

O Programa Sala do Artista Popular (SAP), do Centro Nacional de Folclore e Cultura Popular (CNFCP/IPHAN), foi criado em 1983. Seu objetivo é a pesquisa, documentação, difusão e fomento das artes populares e artesanato tradicional brasileiros. Trata-se de uma proposta que tem início com a seleção de propostas realizadas por uma comissão institucional,

6 Pelas Leis Provinciais $n^{\circ} 1093$ de 07-10-1860 e n. ${ }^{\circ} 3.194$, de 13-09-1884, respectivamente.

7 Duas versões são comumente referidas sobre o topônimo atual da cidade. A primeira de refere ao nome de uma senhora Januária, em cuja casa os aventureiros da região fixavam encontros. Outra, de que seria uma homenagem dada à filha de $D$. Pedro I, princesa Januária.: https://cidades.ibge.gov.br/brasil/mg/januaria/historico. Acesso em 02/03/2019. Seus respectivos distritos são: Januária, Brejo do Amparo, Levinópolis, Pandeiros, Riacho da Cruz, São Joaquim, Tejuco e Várzea Bonita. 
a partir de indicações recebidas do público amplo. Definido um calendário anual de atividades, que pode contemplar em média oito iniciativas (respeitando uma distribuição geográfica no país, perfil de produção e recursos disponíveis para execução), o trabalho se inicia com a criação de uma rede de parcerias possíveis (como secretarias de cultura locais, associações e, fundamentalmente os artesãos contemplando o seu consentimento e participação em suas distintas etapas de trabalho). Em seguida é realizada a pesquisa de campo de cunho etnográfico e mapeamento de informações realizada pelos técnicos da instituição. A pesquisa etnográfica que une teoria e ação é um dos pilares do programa. Apesar de realizada em períodos curtos, ${ }^{8}$ busca atentar para aspectos da obra do artífice, suas formas de trabalho, biografia e contexto, bem como ativar as parcerias locais de modo dialógico. Os dados desta pesquisa dão origem a um catálogo (disponível em formato impresso e on line $)^{9}$ e culmina com uma exposição com venda aberta ao público por 40 dias, em média. São os próprios artífices que decidem o que enviar para o CNFCP, bem como definem os valores dos objetos. Os custos de envio e produção da mostra são franqueados pelo programa. A produção e venda dos objetos feita em parceria com os autores por consignação. No texto de abertura do primeiro catálogo da SAP, Lélia Gontijo - uma das idealizadoras do programa - afirma:

Tal iniciativa vem atender às diretrizes para a operacionalização da política cultural do MEC [Ministério da Educação e Cultura], no tocante à valorização dos bens culturais não consagrados, bem como da proteção do produto cultural brasileiro através do apoio àqueles rituais e formas de representação artesanal, musical, teatral e/ou outras que procedam da experiência coletiva de um grupo pertencente a uma região ou segmento social definido, desde que esteja aí evidenciado um caráter eminentemente popular (GONTIJO, 1983, p. $1)$.

Ainda segundo a autora, o programa estava em acordo com as recomendações da Carta do Folclore Brasileiro (IBECC, 1951) ao proceder na documentação e implementação de ações diretas e indiretas nas comunidades rurais e urbanas em que se encontram os saberes populares. A SAP se alinhava também, segundo Lélia Gontijo, com a perspectiva trazida por Aloísio Magalhães. A de pensar as culturas populares enquanto bens culturais passíveis de serem promotores do desenvolvimento cultural e econômico a partir do incremento de política públicas de cultura (MAGALHÃES, 1985).

8 O tempo de estadia do pesquisador em campo é, em média, de uma semana. Para potencializar esse momento são feitas pesquisas e contatos prévios com os artesãos e rede de parceiros.

9 Para consultar os catálogos da SAP, vide o link: http://www.cnfcp.gov.br/interna.php?ID_Materia=176 acesso em $03 / 01 / 2018$. 
Cabe lembrar que o programa surge em um momento de fortalecimento e consolidação de instituições e linhas de atuação do governo federal no campo da cultura. Na segunda metade da década de 1970 discutia-se, ainda na gestão do governo Geisel, formas mais amplas de se pensar cultura para além do Ministério da Educação e Cultura (MEC). Tais discussões foram o embrião do Centro Nacional de Referência Cultural (CNRC), capitaneado por Aloísio Magalhães e cujos objetivos eram, por meio de ações interministeriais, promover o desenvolvimento econômico, preservação cultural e pensar a identidade nacional a partir dos produtos brasileiros. A produção artesanal e a história das tecnologias nacionais tiveram grande importância neste projeto e enquadravam-se na perspectiva teórica de Magalhães de pensar a nação a partir de sua pluralidade de culturas (CALABRE, 2010; GONÇALVES, 1996). Este contexto está claramente identificado no cerne da proposta da SAP.

Ao longo do tempo o programa tornou-se uma referência possibilitando, para além do reconhecimento simbólico, o escoamento da produção destes indivíduos e grupos, abrindolhes portas para novas oportunidades. Um artista ter o seu nome inscrito na lista dos que passaram pela SAP lhes confere um reconhecimento do valor de sua obra. Ao completar 35 anos de existência a SAP é, sob este olhar, um programa que confere um status diferenciado, de legitimação de indivíduos que produzem um determinado tipo de bens culturais que em geral ficam à margem de um moderno sistema de arte e cultura (CLIFFORD, 1994). Tornouse também o foco de diversos estudos acadêmicos que buscam analisar a sua trajetória enquanto política pública de cultura, as relações entre arte, mercado e patrimônio, bem como o impacto do programa na biografia dos artesãos (SIMÃO, 1998; BAÍA, 2008; POUGY, 2011; MENDES 2016; REIS, 2018; GRIPP, 2019).

Buscando potencializar o protagonismo dos artesãos, o programa incorporou, a partir de 2007, mais uma etapa em seu ciclo de trabalho, o Encontro de Artesãos. A proposta é a de reunir, durante uma semana, os artífices que participaram da SAP ao longo do ano para que possam trocar experiencias entre si. Tem se revelado uma importante ferramenta de diálogo, desencadeando novas redes de parcerias entre os próprios artesãos buscando seu fortalecimento, como explicitado no relato de Vitalino Neto, na primeira edição do evento: "Nós trabalhamos em segmentos diferentes, mas somos todos artesãos. Nós fazemos parte da história desse país, independente do segmento que a gente atue. Por isso eu peço que a gente leve em frente o compromisso de ajudar uns aos outros [...]." (Vitalino Neto, apud Ribeiro, 2007)

Ao longo de sua trajetória o programa SAP desenvolveu ações em Januária em quatro momentos entre 1998 e 2008. Estas ações partiram de mapeamentos prévios realizados pelo 
CNFCP na cidade em 1992 como indicado no catálogo da exposição Mulheres do Candeal impressões no barro de 1998. A curadoria de todos os trabalhos é do antropólogo e então coordenador da Divisão de Pesquisa do CNFCP, Ricardo Gomes Lima. ${ }^{10}$ É ele também quem assina o texto e pesquisa etnográfica de três dos quatro catálogos.

Em "Mulheres do Candeal - impressões no barro (1998)" a produção da louça utilitária é descrita como saber "resultante de um longo processo que compreende pesquisa de matérias-primas, observação da realidade, experimentação de materiais e de técnicas de manufatura, transmitido de geração a geração" (LIMA, 1998, p.20), dividindo espaço com a agricultura de subsistência. Embora considerada um saber amplamente difundido localmente, enfrentava dificuldades naquele momento como a aquisição cada vez mais difícil do barro e o preço baixo obtido na venda dos produtos em um quadro de considerável pobreza.

“Cesteiros de Januária" foi realizada em 2003. Apresenta a cestaria feita pelos irmãos Valdomiro e Valdivino, então com 42 e 39 anos respectivamente, e seus aprendizes. Filhos de um "artesão das várias artes" (PEREIRA, 2003, p.14), seguiram o caminho do pai que se dividia entre o trabalho na lavoura e a produção de objetos utilitários. Em uma família com nove filhos, foram os únicos que permaneceram em Januária e continuar na produção dos cestos, a partir da fibra de bambu.

Já em 2004 foi realizada “O Senhor dos Flandres” que apresenta Irênio Santana, funileiro octogenário recém falecido, cuja presença se fazia ouvir pelas marteladas nas folhas de flandres e zinco no bairro da Rua de Baixo em Januária. Canecas, lamparinas, funis, raladores, baldes, tachos, formas e cuscuzeiras, eram alguns dos objetos produzidos. Com a dificuldade crescente em obter o flandres teve de se adaptar a outras matérias-primas, como o zinco. Para moldá-lo utilizava o recurso de moldes, alguns herdados pelo pai, sendo que boa parte deles eram inteiramente desenhadas e cortadas a mão livre.

Por fim, "Imagens do São Francisco", em 2008 apresenta ao público um conjunto de artistas com linguagens e produção diversas cujo elemento que os une é a presença do Rio São Francisco para vida social e ribeirinha. Seja na madeira, na pintura todos eles documentam a região em sua paisagem cultural, geográfica, personagens e costumes. (LIMA, 2008, p. 8).

As ações desenvolvidas em Januária envolveram a costura com diversas instituições cujas propostas teóricas e políticas podem ser identificadas nos textos de apresentação dos

${ }^{10}$ Posteriormente, Ricardo Gomes Lima realizou sua pesquisa de doutoramento sobre louça de Candeal, concluída em 2006, no Programa de Pós-graduação em Sociologia e Antropologia do IFCS/UFRJ e publicada em livro no ano de 2012. 
catálogos das SAPs. O eminente risco de desaparecimento associado à expansão da globalização, o potencial da atividade artesanal no desenvolvimento cultural e econômico, o aumento da autoestima, da comercialização, dos preços das peças, bem como a importância e precariedade - do mercado municipal como principal (e único) meio de escoamento da produção são recorrentes justificativas apresentadas como impulsionadoras dos projetos.

Neste conjunto de instituições a Prefeitura de Januária e a Sudene ${ }^{11}$ atuaram como parceiras nas ações em Candeal. Nesta, participou também o Programa Artesanato Solidário, atualmente Programa ArteSol ${ }^{12}$. Ruth Cardoso, então coordenadora do programa, destaca a importância da parceria nos seguintes termos:

É essa cerâmica, de cunho bastante utilitário, elaborada a partir de técnicas transmitidas de geração a geração há séculos que é produzida no bairro rural de Olaria, localidade de Candeal, Município de Cônego Marinho, no extremo norte de Minas Gerais. Assolada pela seca e produtora de cerâmica de especial valor cultural e estético, a localidade de Candeal foi escolhida para a implantação de um projeto que visa, por meio do apoio à atividade artesanal, a contribuir para a implantação de um projeto que visa, por meio do apoio à atividade artesanal, a contribuir para a capacitação mão-de-obra, geração de renda e valorização da cultura tradicional, fundamental na elevação da autoestima e no resgate de uma identidade pouco valorizada (CARDOSO, 1998).

A parceria com o Artesanato Solidário é vista também em Cesteiros de Januária. Nesta, Ruth Cardoso apresenta artesanato como um ponto de resistência à fragmentação identitária do mundo moderno: "O artesanato de raiz constitui um contraponto a esse processo na medida em que ressalta identidades locais ligadas à experiência de cada um e de sua comunidade, no espaço que lhe cabe viver" (CARDOSO, 2003, p.7). Cardoso informa da reformulação do programa que coordenava a partir de 2002 visando a ampliação das comunidades assistidas e a abertura da Central ArteSol, uma "via de acesso ao mercado" (CARDOSO, 2003, p.7).

Cesteiros de Januária contou também com a parceria com a Petrobrás. Esta afirmava que a sua presença naquela iniciativa era por meio de seu programa Petrobrás Social voltado

11 A Superintendência do Desenvolvimento do Nordeste foi criada pela Lei $\mathrm{n}^{\circ} 3.692$, de 1959 com objetivo de promover e coordenar o desenvolvimento na região. https://cpdoc.fgv.br/producao/dossies/JK/artigos/Economia/Sudene .

12 Atualmente o Artsol se define nos seguintes termos: "Atuamos na formação dos artesãos nas áreas de identidade cultural, desenvolvimento de produto, gestão, comunicação, comercialização, entre outras, sob os princípios do movimento do comércio justo. Realizamos ações sistemáticas de fomento cultural e incentivo à criação de políticas públicas que fortaleçam e estruturem o setor. Todas as nossas ações são inspiradas nas conexões possíveis entre o artesanato, a arte popular, o design brasileiro, a moda atemporal e todos os aspectos econômicos, socioculturais e ambientais dessas relações.” Fonte: https://www.artesol.org.br/quem-somos. 
para o desenvolvimento dos Indicadores de Desenvolvimento Humano de comunidades carentes. Neste caso, em específico destaca:

Ao apoiar o Projeto Cestaria de Januária, que objetiva a produção e comercialização de cestos e balaios de fibra de bambu, a companhia cumpre o seu papel de incentivar a organização das comunidades auxiliando-as em projetos que gerem renda, emprego e desenvolvimento da população beneficiada. (PETROBRAS, 2003, p. 9).

O Sebrae foi parceiro em O Senhor dos Flandres. A iniciativa estava no âmbito de ação do Projeto Resgate Cultural do Artesanato Mineiro criado em 1999 parte do Programa Sebrae de Artesanato. O texto situa o artesanato mineiro dentro de uma tradição que remonta ao séc. XVIII, o processo de interiorização e a exploração das minas no estado. O risco de extinção é novamente mencionado destacando que: “A preservação da memória dos ofícios artesanais foi, portanto, fruto da necessidade das comunidades e, hoje, os artesãos são guardiões de uma história de desenvolvimento e da cultura de Minas Gerais e do Brasil" (NADDEO, 2004, p.7). O texto destaca ter o Sebrae o objetivo de ampliar a rede de parceiros nesse processo e indica desenvolver também ações em relação às mulheres de Candeal, a cestaria de Januária e os gameleiros de Pedras de Maria da Cruz.

O Senhor dos Flandres contou também com a parceria do então, recém inaugurado Centro de Artesanato de Januária. O texto, não assinado, afirma ter ele surgido da necessidade de um local de referência do artesanato da região. O espaço, sem fins lucrativos, foi pensado por "pessoas identificadas com os fazeres artesanais", embora não as identifique. Contou com apoio de ONGS, instituições públicas, privadas, prefeituras de Januária e Cônego Marinho. Contou ainda, com trabalho voluntário e mantido com percentual de $20 \%$ acrescido ao valor dos objetos vendidos. Seu objetivo:

Concebido como um pólo de comercialização da produção e de formação, reciclagem e apoio a indivíduos e grupos de artesãos, o Centro busca em suas ações abranger a microrregião de Januária, que compreende os municípios de Januária, Cônego Marinho, Bonito de Minas e Itacarambi. (2004, p.9).

Este conjunto de ações apontam Januária enquanto um significativo pólo de produção artesanal no país. Coincidem, de um lado, a retórica de perda cultural (GONÇALVES, 1996) anunciando o eminente risco de desaparecimento de tais práticas dada situação de escassez local; e de outro, o potencial de desenvolvimento econômico alavancado a partir da cultura. $\mathrm{O}$ entendimento sobre este potencial, no entanto, varia de acordo com a proposta e característica de cada instituição que ali atua conforme indicamos. Permite observar também o caráter episódico da maioria deles, visto que não encontramos dados sobre desdobramentos dos 
mesmos. Configuram assim, um conjunto de ações datadas no tempo e espaço cujos impactos acabam comprometidos em função da ausência de perspectiva de continuidade.

Em relação a atuação da SAP na região, em específico, notamos como o programa buscou diálogo com uma diversificada rede de agentes e instituições de naturezas distintos ao longo de dez anos, intervalo de tempo entre a sua primeira e a última ação. Notamos também que o trabalho desenvolvido em Januária reflete uma característica que o acompanha em sua trajetória. Algumas de suas ações são decisivas para fomentar determinados nomes e alavancá-los no circuito de arte e cultura popular no país e, mais recentemente, exterior. No caso em questão, a cerâmica de Candeal talvez tenha sido o caso mais bem sucedido, visto ter se tornado uma cerâmica nacionalmente conhecida e valorizada. Outros, acabam com um impacto pequeno, o que parece ter sido o caso das demais ações com uma fomentação mais ligada ao comércio local. Fatores como interesse despertado pelo mercado, a capacidade de articulação e produção dos artesãos, dificuldades de acesso a matéria prima e escoamento, bem como transmissão desse conhecimento são alguns dos fatores que concorrem para tal. Soma-se também as limitações de uma instituição pública, como o CNFCP, para o acompanhamento mais preciso e eficaz de tais ações, com reduzido quadro técnico e orçamentário.

\section{O Ponto de Cultura de Januária}

O Programa Ponto de Cultura foi criado ainda no primeiro governo do presidente Luíz Inácio Lula da Silva. Inseriu-se dentro de uma proposta mais ampla de reconfiguração da política federal de cultura no Brasil, fazendo com que houvesse uma maior regionalização da gestão cultural, numa tentativa de, corrigindo erros dos modelos de governos anteriores, capilarizar a distribuição dos recursos voltados à área. A seleção dos Pontos de Cultura pelo Ministério da Cultura foi feita a partir do lançamento do edital público Programa Cultura Viva, em setembro de 2005. Segundo um de seus idealizadores tratava-se de uma proposta de política "de baixo para cima", como afirma:

A aplicação do conceito de gestão compartilhada e transformadora para os Pontos de Cultura tem por objetivo estabelecer novos parâmetros de gestão e democracia entre Estado e sociedade. No lugar de impor uma programação cultural ou chamar os grupos culturais para dizerem o que querem (ou necessitam), perguntamos como querem. Ao invés de entender a cultura como produto, ela é conhecida como processo. Este novo conceito se expressou com o edital de 2004, para seleção dos primeiros Pontos de Cultura. Invertemos a forma de abordagem dos grupos sociais e o Ministério da Cultura disse quanto podia oferecer e os proponentes definiam, a partir de 
seu ponto de vista e de suas necessidades, como aplicariam os recursos. Em algumas propostas o investimento maior vai para a adequação física do espaço, em outras para a compra de equipamentos, ou como na maioria, para a realização de oficinas e atividades continuadas. $\mathrm{O}$ único elemento comum a todos é o estúdio multimídia, que permite gravar músicas, produzir audiovisual e colocar toda a produção na internet. (TURINO, 2009, p.64)

O objetivo do programa era "ampliar e garantir o acesso aos meios de fruição, produção e difusão cultural existentes no Brasil, estimular e facilitar o envolvimento da população nas diversas manifestações culturais e promover a cultura enquanto expressão e representação simbólica, de direitos e econômica" (CULTURA VIVA, 2005, p.10). O conceito do Programa é o de estimular iniciativas agregando "recursos e novas capacidades a projetos e instalações já existentes" (idem, grifo nosso) que estejam sendo conduzidas por coletivos, associações e grupos, organizações não-governamentais e instituições públicas, apoiando-se nos conceitos de associativismo, protagonismo, empoderamento e apontando para cinco eixos de atuação: Pontos de Cultura, Cultura Digital, Agente Cultura Viva, Ação Griôs e Escola Viva. A rede de Pontos de Cultura, espalhada em milhares de polos pelo país, tem como referencial o "estímulo à exploração de diferentes meios e linguagens artísticas e lúdicas, bem como à inclusão digital, percebendo a cultura em suas dimensões de construção simbólica, de cidadania e direitos e de geração e distribuição de renda" (MINC, 2006). Foi nesse contexto que, entre os anos de 2005 e 2009, foi implementado na cidade de Januária o Ponto de Cultura Música e Artesanato: cultura tradicional no norte de Minas.

Já no início de sua implantação, o Ponto de Cultura envolveu a participação de indivíduos, coletivos e instituições no planejamento conjunto e consensual das ações que seriam desenvolvidas. Esse tipo de proposta participativa fez parte de uma estratégia metodológica que também já vinha sendo adotada nas SAPs conduzidas na região. Como foi dito, a cidade de Januária já vinha sendo objeto de políticas culturais voltadas para as chamadas manifestações populares tradicionais desde pelo menos a década de 1960 quando foi objeto de investigação etnográfica feita na região pelo pesquisador Joaquim Ribeiro para a Campanha de Defesa do Folclore Brasileiro (FONSECA, 2009). A partir de 2004, porém, em decorrência também desse conjunto de iniciativas então conduzidas pelo CNFCP, um grupo de agentes culturais criou na cidade o Centro de Artesanato de Januária compondo um coletivo que passou a implementar uma série de ações de promoção tanto do artesanato quanto de grupos e manifestações culturais populares e tradicionais. Em seu início em 2004, a proposição e administração do projeto do Ponto de Cultura do Centro de Artesanato de Januária foi feita pela Associação de Amigos do Museu Edison Carneiro/ACAMUFEC, 
organização da sociedade civil que atua no apoio às atividades do CNFCP/IPHAN. Isso ocorreu para que fosse possível viabilizar a proposição junto ao Ministério da Cultura já que na ocasião o Centro de Artesanato ainda não se encontrava juridicamente regularizado para poder encaminhar a proposta.

Em termos de política pública para o campo cultural, o programa do Ponto de Cultura era uma novidade para muitos polos espalhados pelo Brasil, embora no caso de Januária, inúmeras ações já tivessem sido ou estivessem sendo implementadas na região. Como vimos, o CNFCP/IPHAN já havia realizado SAPs com diversos artistas, artesãos e comunidades locais, promovendo ações de valorização de suas produções artesanais e conseguindo induzir a organização daquele grupo de agentes em torno da promoção, valorização e comercialização dessas produções no Centro de Artesanato da Januária. No entanto, o campo da implementação de políticas voltadas para a promoção especificamente de grupos de música tradicional colocava novos desafios para esses agentes. Nesse sentido, e no âmbito do Ponto de Cultura, a possibilidade de definir conjuntamente com esses agentes o modo como a implantação das ações de política pública deveriam ocorrer determinou uma nova e desafiadora qualidade de relacionamento com os grupos de música tradicional, o que necessitou envolver a todos como protagonistas dessas iniciativas.

De todas as iniciativas de promoção implementadas nesse sentido, pelo Ponto de Cultura, trataremos aqui das práticas musicais ligadas às expressões performativas tradicionais, especialmente, aquelas representadas pelo grupo de reisado Terno dos Temerosos. O Terno dos Temerosos é conhecido por "Reis dos Cacetes" pois seus integrantes saem em marcha pelas ruas da cidade, cantando e percutindo seus bastões uns contra os outros para marcar o ritmo do bailado que executam como mais uma das manifestações que celebram a epifania católica no período de 25 de dezembro e 06 de janeiro. Oriundo do bairro da Rua de Baixo de Januária, entoam cantigas de um repertório tradicional e popular, realizando um circuito de visitas para celebração nas casas de parentes, conhecidos e simpatizantes, por diversos bairros da cidade.

As ações de promoção do Terno buscaram repensar o papel de suas performances musicais públicas frente ao panorama dos contextos culturais do município, o que incluía refletir tanto sobre os circuitos de shows artísticos como sobre, até mesmo, aqueles circuitos mais ligados às práticas musicais de caráter religioso por exemplo. Nesta investigação foi preciso mapear a trajetória e alguns dos principais aspectos históricos do Terno do Temerosos. 
Já nos contatos iniciais feitos com João Damasceno, líder do grupo, e alguns de seus integrantes, três desejos foram explicitamente manifestados: a gravação de seu repertório em Compact Disc-CD; uma maior divulgação do grupo e uma terceira ainda mais ambiciosa, que era a transformação da sua residência em um centro cultural que pudesse oferecer uma gama de atividades culturais e educacionais à comunidade da Rua de Baixo.

Iniciamos com a realização da gravação, senão de todo, de parte significativa do repertório musical do grupo e sua posterior conversão para $\mathrm{CD}$, o que possibilitou não só a geração de um acervo musical mas também de sua utilização posterior em apresentações pela região através do processo de playback. A gravação desse repertório foi o primeiro passo na direção de inserção do grupo nas propostas de uma das partes do programa, a chamada Cultura Digital. Posteriormente foi feita a remasterização sonora dos registros fonográficos antigos, gravados por Joaquim Ribeiro na década de 1960 e outros realizados recentemente, tendo resultado na produção e prensagem, financiada CNFCP, de um CD duplo onde podem ser encontrados também textos, partituras e fotos do grupo. Como produto de uma política com financiamento público, esse CD não teve finalidade lucrativa e tem sido utilizado desde então como forma de divulgação do grupo em suas viagens, alavancando, conforme desejado pelo grupo, suas apresentações de performance.

Das aspirações manifestas pelo grupo, a transformação da residência de Damasceno em um centro cultural só foi possível a partir da conquista do prêmio de R \$ 10.000,00 obtidos no concurso "Prêmio Culturas Populares - Mestre Duda 100 anos de Frevo" promovido pelo Ministério em Cultura de 2007, que premiou grupos populares tradicionais. O edital do prêmio havia sido publicado naquele ano, tendo sido repassado à ACAMUFEC, e os membros do Ponto de Cultura que resolveram inscrever o Terno do Temerosos. Com esse recurso em mãos foi possível sensibilizar e promover a articulação de um conjunto de agentes e instituições públicas e privadas de Januária no sentido de fazê-los ver a importância da criação de mais um espaço voltado para promoção cultural no município. Ao contrário do Centro de Artesanato que se situa no centro da cidade, a Casa de Cultura Berto Preto foi criada na região onde se localiza o Terno, na Rua de Baixo, tendo recebido esse nome como homenagem ao folião que o fundou por volta da década de 1950.

É preciso constatar que todo esse processo de condução de ações de política pública se deu, também no Ponto de Cultura de Januária, permeado por idiossincrasias que são inerentes às propostas participativas. Especialmente no campo das políticas culturais, as táticas e projetos de ação jamais podem ser de antemão definidos, necessitando ser debatidos em função dos objetivos que pretendem atingir. 
Consideramos que as políticas voltadas para o campo da cultura devam ser processos por meio dos quais seja possível garantir a indivíduos e variados grupos sociais, a partir de ações sistemáticas do Estado, a expansão e equalização de oportunidades de acesso à produção, criação, difusão e fruição de bens e expressões culturais, potencializando os agentes para se tornarem protagonistas dessas ações. J.J. Brunner aponta o Estado, o mercado e as comunidades e grupos sociais como "instâncias organizacionais" (BRUNNER, 1985) que se encontram em inter-relação com o campo das políticas culturais. Brunner refere-se especialmente ao papel das políticas públicas na atuação sobre o que chama justamente de circuitos culturais, enquanto mecanismos de valorização simbólica.

A adoção, no debate sobre políticas públicas, da ideia de circuito desloca a não rara perspectiva que trata a cultura como um conjunto de objetos e aponta mais para a circulação e o trânsito de bens e processos culturais. Nos termos da socióloga Ruth Finnegan, que acompanhou durante mais de 20 anos as práticas musicais da cidade inglesa de Milton Keynes, realizando uma descrição densa dos chamados "mundos musicais", estes circuitos se conformariam não somente por seus "estilos musicais, mas também por outras convenções sociais: as pessoas que dele tomam parte, seus valores, suas práticas e entendimentos compartilhados, modos de produção e distribuição, e a organização social de suas atividades musicais coletivas" (FINNEGAN, 1989, p. 32). Desse modo, apesar das intervenções das políticas públicas implementadas pelo Ponto de Cultura de Januária no âmbito das práticas musicais performativas terem desencadeado algumas ressignificações e rearranjos nos circuitos culturais regionais, muitas das ações não obtiveram o resultado esperado e/ou desejado.

Detentores de um certo capital simbólico, o Terno dos Temerosos são negociadores ativos frente às forças que atuam nos circuitos culturais de Januária. Festivais folclóricos, eventos municipais, feiras, escolas públicas são alguns dos espaços pelos quais têm circulado, e nos quais os registros audiovisuais e fonográficos realizados com eles têm cumprido papéis importantes. A partir do projeto do Ponto de Cultura, o desafio colocado ao Terno dos Temerosos é a possibilidade de que a Casa de Cultura Berto Preto, surgida nesse bojo, possa cada vez mais se consolidar como referência no circuito cultural local, desafio que eles, autonomamente, deverão conduzir, esperando sempre contar com a parceria e a colaboração não só de agentes locais mas também, em nível nacional, com instituições como o CNFCP. Por outro lado, na prática é preciso observar que o campo cultural se coloca hoje em Januária, e em outras regiões, como "espaço de jogo de uma luta concorrencial” (BOURDIEU, 1983, p. 122), onde a atuação de variados agentes culturais reflete uma convivência nem sempre 
harmônica ou colaborativa. Refletindo variadas tendências e orientações, essa luta se dá a partir de posições e conflitos estilizados que têm na arena das políticas públicas um lugar privilegiado de disputa pela distribuição e hegemonia das diversas espécies de capitais simbólicos e materiais distribuídos nesse jogo (BOURDIEU, 1974).

\section{Notas finais}

Iniciamos a argumentação deste artigo comentando sobre as dificuldades de se definir, executar e gerir políticas públicas no mundo atual, bem como a importância de que estas, cada vez mais, incorporem seus interlocutores ou o público a que se destinam, como agentes ativos desde seu processo de elaboração. Focamos em um território em específico, a cidade de Januária (MG), procurando entender de forma mais acurada a incidência de ações ali implementadas ao longo de um recorte temporal específico. Analisando dois programas em particular, notamos diferentes formas de se pensar - ou não - no desenvolvimento de processos "participativos" ou "colaborativos", voltados para os saberes tradicionais. Pudemos inferir que, se de um lado, se coadunam com a crescente preocupação e importância na participação social na elaboração de projetos; de outro permite ver no quanto tais propostas podem variar quanto aos seus graus de interação entre sujeitos proponentes e agentes culturais envolvidos em tais ações e, por consequência que impacto proporcionam. De modo amplo, observamos a presença do Estado e organizações civis agindo ao mesmo tempo e ao longo de décadas com projetos que apontam como horizonte comum a cultura como ferramenta de desenvolvimento social. De modo específico, o quanto seus discursos e metodologias oscilavam do salvacionismo oriundo de um projeto verticalizado até aquelas que envolveram uma perspectiva transversal e participação ativa da comunidade local. Pareceu-nos assim, oportuno encerrar nosso argumento com uma breve reflexão sobre os possíveis alcances destas práticas e os justos sentidos de protagonismo que de fato almejam, especialmente porque, não raramente, envolvem algum assédio em torno dos ditos "saberes populares".

Num plano mais geral, ao longo destas últimas três décadas ocorreram muitas mudanças no campo das chamadas artes populares. Algumas questões encontram-se na agenda do dia como as discussões sobre patrimonialização, identidade, memória, um mercado e colecionamento dessas obras parece cada vez mais forte e consolidado, além questões sobre autoria e propriedade intelectual, para citar alguns exemplos. O desafio dos programas propostos no âmbito das políticas culturais é o de manterem-se sempre atuais em relação a este cenário, dialogando com os detentores de saberes tradicionais de forma horizontalizada e 
que tenha como perspectiva a autonomia destes grupos ou, o previsto direito à cultura e cidadania previsto na Constituição de 1988.

Sobre a SAP, notamos a presença de um programa que busca fazer valer uma proposta de participação de seus interlocutores, bem como preceitos de cidadania e democratização cultural. A proposta de trabalho transversal do programa reside no modo em que busca fortalecer o artesão enquanto sujeito e detentor de um saber único - e não seus produtos como coisas isoladas de seu autor - ao buscar criar redes de parceiros locais, que tenham acesso a canais diretos de venda de suas peças, com liberdade de escolha de preços e contato direto com seu consumidor final, minimizando atravessadores. Busca trazer sua voz enquanto principal protagonista sendo ele elemento ativo em várias decisões sobre a execução do programa. Por esta razão, cabe enfatizar, a SAP trouxe uma perspectiva bastante inovadora para o tempo em que foi criado e, em grande medida até os dias atuais. Não por acaso, continua sendo uma referência nesta área.

Em relação aos Pontos de Cultura, ao longo de sua história o programa passou por turbulências e propostas de reformulação visando a sua otimização. Se capilarizou em redes estaduais, municipais e, conta hoje, mais de 4 mil iniciativas em atividade, segundo dados oficiais $^{13}$. Quando foram lançados tinham o claro objetivo de construção de políticas transversais frente a outros programas de Estado, como, por exemplo, o Economia Solidária do Ministério do Trabalho e Emprego. Nas palavras de seu idealizador, Célio Turino,

a integração dos dois programas está dentro de uma visão mais ampla de cultura, em que ela assume caráter, não apenas de expressão simbólica mas, de enfoque sobre a economia. Trata-se de concepção já abordada pela ONU sob o aspecto do desenvolvimento social. A parceria assume a característica de concretizar expectativas de geração de renda a partir de atividades culturais (MTE, 2010).

Para a realidade da maioria dos Pontos, é ainda pequena a possibilidade de que dos jovens que participam do programa, de fato, façam dessas práticas e ofícios seus meios de vida. A inserção dos produtos gerados no mercado não pode ser solucionada somente com a implementação de projetos culturais como esse, o que coloca desafios a um dos conceitos básicos do programa dos Pontos, a ideia de "empoderamento". De toda forma, para alguns indivíduos, é provável que as experiências vividas em programas como o do Ponto de Cultura, mesmo não tendo "resultados profissionais" imediatos e/ou permanentes, se reflitam no futuro como alternativas de cidadania e mesmo de sobrevivência, apesar do atual e significativo enfraquecimento ou mesmo esvaziamento de todo o conjunto das políticas culturais.

13 Vide: http://culturaviva.gov.br/busca/\#\#(global:(enabled:(agent:!t),filterEntity:agent,map:(center:(lat:15.813395760460573,lng:-47.87841796875),zoom:5))). Acesso em: 03/02/2019. 
Por fim, e a partir destes dois casos, identificamos algumas questões mais amplas. Em primeiro lugar, um ponto comum a salientar é a dificuldade de executar políticas públicas voltadas para os segmentos populares com a participação dos mesmos. A estrutura burocrática do estado brasileiro não dialoga com a realidade destas populações. Dados como documento de identificação, conta corrente em banco, acesso à internet, prestação de contas com notas fiscais e preenchimento de uma série de formulários, são realidades frequentemente distantes destes grupos. Estabelece-se uma relação sempre desigual, em que os grupos têm de se adequar ao estado para serem agraciados por tais políticas. ${ }^{14}$

Não obstante, nos tempos atuais o papel do estado é o de oportunizar mecanismos sustentáveis para um diálogo mais equitativo entre as instâncias organizativas, para uma maior igualdade de condições de valorização, produção e difusão dos bens e expressões culturais. Para isso é necessário reforçar e/ou constituir canais de comunicação entre Estado, agentes culturais e demais interlocutores possíveis, e que estes possam atuar de forma ativa na formulação, implementação e avaliação dessas políticas.

Quanto a isto cabe sublinhar que tanto a antropologia como a etnomusicologia brasileiras têm hoje uma crescente cumplicidade com as políticas públicas de cultura no país. A ampliação das linhas de financiamento trouxe uma enorme demanda pela participação de pesquisadores em projetos diversos. Essa participação poderá ser mais efetiva na medida em que incluir a consciência de que deva ser feita sob uma avaliação crítica não só de seus contextos, mas frente às próprias ações de política cultural da qual fazem parte e, sobretudo, a quem se destinam.

O papel dos pesquisadores neste sentido é, para além da reflexão teórica, a de romper a distância entre distintos sistemas de saberes e relações de poder. De atuar no diálogo nas diferentes etapas do desenvolvimento do processo em distintas instâncias; acadêmica, jurídica, política. Proporcionar discursos e práticas inteligíveis entre pessoas separadas por diferentes assimetrias e potencializar a presença ativa dos detentores destes saberes ao longo destes processos.

14 Mesmo em ações mais recentes como aquelas que emergiram com a política voltada ao patrimônio imaterial, bem como a proposta metodologia de inventários participativos, ainda há dificuldade em superar as estruturas burocráticas que acabam por contribuir para exclusão de determinados grupos. 


\section{Referências Bibliográficas}

ARAÚJO, S. Características e papéis dos acervos etnomusicológicos em perspectiva histórica. In: ARAÚJO, S.; PAZ, G.; CAMBRIA, V. (Orgs.) Música em debate. Rio de Janeiro: Mauad X: FAPERJ, 2008.

BAÍA, Luiz C. Sala do Artista Popular: Tradição, identidade e mercado. Dissertação de mestrado em Museologia e Patrimônio. Rio de Janeiro, UNIRIO/PPG-PMUS, 2008.

BOURDIEU, Pierre. O mercado dos bens simbólicos. In: A economia das trocas simbólicas. (org. Sérgio Miceli). São Paulo: Perspectiva, 1974.

Ortiz). São Paulo: Ática, 1983.

Trabalhos e Projetos. In: Pierre Bourdieu: sociologia. (org. Renato

BRUNNER. J.J. La cultura como objeto de políticas. Documento de Trabajo. Programa Flacso - Santiago de Chile, no. 74, Ouctubre, 1985 b.

CALABRE, Lia. Políticas culturais no Brasil: História e contemporaneidade. In: Coleção textos Nômades. N 2 Fortaleza: Banco do Nordeste, 2010.

\section{Escritos sobre políticas culturais. RJ: Casa de Rui Barbosa, 2019.}

CANCLINI, Nestor. Definiciones en transición. 2001. Disponível em: http://biblioteca.clacso.edu.ar/clacso/gt/20100912035750/5canclini.pdf. Acesso em: 25/05/2017

CAMBRIA, Vincenzo; FONSECA, Edilberto, GUAZINA, Laize. "With the People": Reflections on Collaboration and Participatory Research Perspectives in Brazilian Ethnomusicology. The World of Music New Series. Vol. 5 (2016) 1, p. 55-80.

CARDOSO, Ruth. Apresentação. In: Mulheres do Candeal - Impressões no barro. Sala do Artista Popular n.76. RJ: Funarte, 1998.

110. RJ: Funarte, 2003

Apresentação. In: Cesteiros de Januária. Sala do Artista Popular n.

CLIFFORD, James \& MARCUS, George. Writing Culture: The Poetics and Politics of Ethnography. Berkeley: University of California Press, 1986.

CLIFFORD, James. A experiência etnográfica: antropologia e literatura no século XX; 2.ed. Rio de Janeiro: Editora UFRJ, 2002.

Colecionando arte e cultura. IN: Revista do Patrimônio Histórico e

Artístico Nacional. N. 23, 1994.

COELHO, Teixeira. Dicionário crítico de política cultural. SP: Fapesp/Iluminuras, 2004.

CULTURA VIVA. Caderno da Ação Agente Cultura Viva. Brasil: Ministério da Cultura, 2005.

FINNEGAN, Ruth. The Hidden Musicians: Music-Making in an English Town. Cambridge: Cambridge University Press, 1989.

FONSECA, Edilberto J. de M. Temerosos reis dos cacetes: uma etnografia dos circuitos musicais e das políticas culturais em Januária - MG. Tese (Doutorado em Música), Programa de Pós-Graduação em Música, Universidade Federal do Estado do Rio de Janeiro, Rio de Janeiro, 2009.

GAJARDO, M. Pesquisa participante: propostas e projetos. In: BRANDÃO, C.R. (Org.) Repensando a pesquisa participante. São Paulo: Brasiliense, 1999.

GONÇALVES, José Reginaldo. A Retórica da Perda. RJ: EDUFRJ, 1996.

GONTIJO, Lélia. Jota Rodrigues. Sala do Artista Popular: Implantação. IN: Folhetos, romances/literatura de cordel. RJ: CNFCP/Funarte,1983 (Catálogo SAP nº1)

GRIPP, Maria. A experiência da sala do artista popular (sap): engajamentos e encaixes de uma política pública de cultura. Dissertação de Mestrado. RJ: UFF, 2019. 
GUAZINA, Laíze. Etnomusicologia, política e debate social: contribuições para um estado da arte da etnomusicologia participativa no Brasil. Anais do VII Encontro Nacional da Associação Brasileira de Etnomusicologia. UFSC, Florianópolis, de 25 a 28 de maio de 2015. GUAZINA, L. Etnomusicologia brasileira, participação e educação: reverberações a partir do Sul. In: Revista Brasileira de Música. V. 31, N.2, p. 11-13, Jul-Dez 2018.

HERNANDEZ, Omar. Antropología aplicada e investigación participativa. Cuadernos de Antropología. Revista Digital del Laboratório de etnologia. Vol. 5 1986. Disponível em: http://revistas.ucr.ac.cr/index.php/antropologia

IBECC. Anais do $1^{o}$ Congresso Brasileiro de Folclore, I vol. Rio de Janeiro: Serviço de Publicações, Ministério das Relações Exteriores, 1951.

IMPEY, Angela. Culture, Conservation and Community Reconstruction: Explorations in Advocacy Ethnomusicology and Participatory Action Research in Northern Kwazulu Natal. Yearbook for Traditional Music. Vol. 34, pp. 9-24, 2002.

INSTITUTO NACIONAL DE CIÊNCIA E TECNOLOGIA DE INCLUSÃO NO ENSINO SUPERIOR E NA PESQUISA. Encontro de Saberes: bases para um diálogo interepistêmico. Brasília, 2015.

LIMA, Ricardo Gomes. Mulheres do Candeal - Impressões no barro. Sala do Artista Popular n. 76. RJ: Funarte, 1998.

2004.

O Senhor dos flandres. Sala do Artista Popular N. 122. RJ: Funarte, Imagens do São Francisco. Sala do Artista Popular. N.147. RJ:

Funarte, 2008.

2012.

O povo do Candeal: Caminhos da louça de barro. RJ: Aeroplano,

LÜHNING, A.; CARVALHO, T.; DINIZ, F.; LOPES, A. R. et al. Desafios da etnomusicologia no Brasil. In: LÜHNING, A.; TUGNY, R. (Orgs.). Etnomusicologia no Brasil. Salvador: EDUFBA, 2017.

MAGALHÃES, Aloísio. E Triunfo? A questão dos bens culturais no Brasil. RJ: Nova Fronteira/Fundação Pró-memória, 1985.

MENDES, Sérgio P.C. Patrimônio Cultural e o Mercado de Arte Popular: a institucionalização da Sala do Artista Popular. Tese. Campinas, São Paulo, 2016. 263p.

MINC. Ministério da Cultura. Disponível em www.cultura.gov.br. (Acesso em: 11/2006).

MTE. Ministério do Trabalho e Emprego. Disponível em www.mte.gov.br (acesso: 11/2010)

NADDEO, Maia Dorotéa de Aguiar Barros. Resgate do artesanato tradicional de Minas Gerais. IN: LIMA, Ricardo Gomes. O Senhor dos flandres. Sala do Artista Popular N. 122. RJ: Funarte, 2004.

OSÓRIO, Patrícia. Os festivais de cururu e siriri. Mudanças de cenários e contextos na cultura popular. IN: Anuário Antorpológico. Brasília, 2012.

PEREIRA, Tereza Cristina do Carmo. Cesteiros de Januária. Sala do Artista Popular. N.110. RJ: Funarte, 2003

PETROBRÁS. Apresentação. Cesteiros de Januária. Sala do Artista Popular. N.110. RJ: Funarte, 2003

POUGY, Elizabeth. Programa Sala do Artista Popular. In: II Seminário de Investigación em Museología de los países de lengua portuguesa y española, ICOM, Buenos Aires, Argentina, 2011.

REIS, Daniel. Objetos em Trânsito. Usos e circulação de uma boneca gigante em Maceió. (Tese de Doutoramento) RJ, 2013.

Programa Sala do Artista Popular: um espaço de encontros, trocas e democratização de culturas. In: e-cadernos CES [Online], n.30, 2018.

RIBEIRO, Andrea (2007), "Relatório do Encontro de Artesãos". Rio de Janeiro: CNFCP. 
RIBEIRO, Joaquim. Folclore de Januária. Rio de Janeiro: Campanha de Defesa do Folclore Brasileiro, 1970.

RUBIM, Antônio Albino Canelas. Cultura e Políticas Culturais. RJ: Azougue Editorial, 2011 SHELEMAY, Kay Kaufman. The Ethnomusicologist, Ethnographic Method, and the Transmission of Tradition. In: BARZ, Gregory F. e COOLEY, Timothy J. (orgs.). Shadows in the Field: New Perspectives for Fieldwork in Ethnomusicology. New York: Oxford University Press, 1997, p. 189-204.

SIMÃO, Luciene de Menezes. O artista popular em sua sala: poética de exposição. Dissertação Mestrado História. Rio de Janeiro, PUC, 1998

THIOLlENT, M; OLIVEIRA, L. Participação, cooperação, colaboração na relação dos dispositivos de investigação com a esfera da ação sob a perspectiva da pesquisa-ação. Atas Congresso Ibero-Americano em Investigação Qualitativa - CIAIQ. Investigação Qualitativa em Ciências Sociais. Vol. 3, 2016.

TRAVASSOS, Elizabeth. Esboço de balanço da etnomusicologia no Brasil. Opus: Revista da Associação Nacional de pesquisa e Pós-Graduação em Música - ANPPOM - ANO 9, n. 9 (dez. 2003) - Campinas (SP): ANPPOM, 2003. p. 73-86.

TURINO, Célio. Ponto de Cultura: o Brasil de baixo pra cima. SP: Anita Garibaldi, 2009.

VILHENA, Luís Rodolfo. 1997. Projeto e Missão. O Movimento Folclórico Brasileiro, 19471964. Rio de Janeiro: Funarte/Fundação Getúlio Vargas, 1997. 